\title{
Distance of Closest Surgical Margin
}

National Cancer Institute

\section{Source}

National Cancer Institute. Distance of Closest Surgical Margin. NCI Thesaurus. Code C137815.

The distance of the closest surgical margin from tumor after surgical resection of the tumor. The closest distance between a tumor and its resection marg in has prognostic significance. 